\title{
Future of the news function of printed press under the competition of electronic communications: a prospective study in the period 2015-2025
}

\author{
Heba Goda Ahmed Awad ${ }^{\mathrm{a}, 1, *}$ \\ Ibrahim Laila Abd Elmagid ${ }^{\text {b, } 2}$ \\ a, b faculty of mass communication cairo university, Gamaa Street, Giza 12613, Egypt \\ ${ }^{1}$ heba.goda@aou.edu.eg* \\ 2 abdelmagid.laila@gmail.com \\ * corresponding author
}

ARTICLE INFO

\section{Article history}

Received 2019-07-29

Revised 2019-09-09

Accepted 2019-09-19

Keywords

Future

News Function

Printed Newspaper

Electronic Communications

Technological Development

\section{ABSTRACT}

The technological development has led to the emergence of modern means of communication, such as electronic newspapers, tablets and mobile phones. Since modern communication media has assumed growing responsibility in the reporting and dissemination of news and information, printed media has been negatively affected. This paper aims to investigate the future of the news function of printing press under the competition of electronic means in the period 2015-2025 by determining the factors affecting this function, the experts' perceptions and the possible future scenarios. By conducting interviews with experts and analyzing the contents of news items in printed and electronic newspapers, this article reveals that printed press cannot be dead because it is more effective in shaping the reader's agenda and still adheres to professional norms. Results add that online news content lacks the professional guidelines, especially the accuracy and the attribution as many of the quotes are inaccurate, or are attributed to the wrong person due to the uncontrolled freedom of posting and modifying information online.

This is an open access article under the CC-BY-SA license.

\section{Introduction}

As we know, nowdays the printed press in the whole world is facing a competition with the electronic means of mass communication which have caused a crisis that threatens the survival of printed press owing to the decline in its industry, its inability to meet the readers' diverse needs and the erosion of its credibility [1]. This leads to low distribution rate of printed newspapers, and thus, drop in printed advertising revenues on the contrary to the electronic means of communication revenues.

The development of modern technologies has led to the emergence of the internet which carries a vast range of information resources. The recipients have turned to the internet to get more 
information on any topic. So, it has become an interactive means of mass communication [2]; it has proven to be more effective, more rapid and well-appreciated medium.

The internet has combined the advantages of both printed newspapers and television broadcast; it provides the news story with photographs, audio and video, so it enables the receiver to watch the events as they unfold [3]. The internet has great potential for the dissemination of data due to its unlimited space, and keeping abreast of the latest developments and issues [4]. These features distinguish the online newspapers from the printed ones which have limitations of time and space in a way affecting the quality of news coverage [5].

The Economist published an article assures that Rupert Murdoch was right to predict the end of newspapers as we now know them. The article says in part that "the decline of newspapers predates the internet. But the second - broadband - generation of the internet is not only accelerating it but is also changing the business in a way that the previous rivals to newspapers-radio and TV-never did. Older people, whom Mr Murdoch calls "digital immigrants", may not have noticed, but young "digital natives" increasingly get their news from web portals such as Yahoo! or Google, and from newer web media such as blogs" [6].

Online journalism now becomes a new chapter in the journalism world. Paper technology is increasingly being expelled by internet technology. Various press companies are rolled, either domestically or internationally. Then they transfer their business to the online media. Because it is judged faster, environmentally friendly, and efficient. The presence of Internet-based online media shifts its implications, the success of newspapers and other paper-based media.

Moreover, evidently, the Internet has now juggle conventional industries, becoming a digitalbased industry. One of them is the mass media industry. Until now, mass media is believed to be the most powerful tool in influencing public opinion. The rapidly growing media, electronic media, and online media industry today emphasize the mass media business is a much-loved businessman business. The current trend, the expansion of conventional mass media to Internet-based online media is increasingly vibrant.

The advantages of online media that are far superior in delivering speed, the content is more varied and widely reached, accessible to all audiences around the world, and economically very cheap, making a lot of media company management Print changes its format to online media. Along the way, the profession of online journalists becomes very prospective, in the calculation of economic and idealism. Moreover, now, everyone can become an online journalist. The popular term, everyone can be citizen journalism. By becoming an online journalist, everyone is more comprehensive and flexible in conducting various reportage activities. Finally, competition between online media becomes an inevitable necessity. Only the online media supported by the management of editorial and management of the professional corporation, finally a winner in the middle of the sting media industry (print media, electronic media, and online media).

The authority, public readiness in the homeland in utilizing online media as information media, entertainment, education, and supervision, is still questionable. The majority of Indonesians who are still not media literate, strengthen how public awareness in utilizing print media, let alone online media is still quite low. That is the challenge that all elements of the nation must answer. By optimizing the use of online media and making everyone, an online journalist and or citizen journalism will accelerate national development.

Technology truly becomes a prima for modern human civilization in the XXI century. The characteristic of technology is an applicative, simple, and easy way of human life. Technology that increasingly complicates human life means not in the category of technology. Internet Technology (digital) becomes one of the most significant icons of technology products in these modern times. The massive expansion of the conventional media industry to the Internet-based media has been in the past since the beginning of 2000 years ago, and its peak later predicted in the year 2022 upcoming.

Nowadays, online journalism becomes a new chapter for world journalism in the world and the homeland. The parameters are obvious. Various newspapers in the world have been in recent years competed to develop the media industry by accommodating as many aspirations of its readers, especially by developing sites online. Then it is inevitable; every newspaper has an online site. It 
was an anticipatory step by the newspaper management so that they did not lose their loyal readers, who began to abandon media trends from the paper era to the digital age [7].

Learning from the case of the roll-up of The industry's oldest newspaper company of Caliber The New York Times in the United States in late 2011, it became a heavy blow to the worldwide print entrepreneurs. The New York Times had to sell 16 regional newspapers to Halifax Media Holdings for USD 143 million. The newspaper was sold, among others, the Sarasota Herald-Tribune, The Ledger in California, the Herald-Journal in North Carolina, The Press Democrat in California, StarNews in Wilmington, the Daily Comet in Los Angeles and ten other regional newspapers which reached 430 thousand copies.

The New York Times "Emergency" step sells its regional newspaper companies to address the Company's debt burden. Where throughout the year 2011 experienced an extraordinary ad decline. As an illustration, during the first nine months of 2011, the Company's revenue fell drastically by 7 percent, or only USD 190 million. In the year 2010, the annual revenue of the US-leading newspaper company in the United States as high as USD 2.4 billion (Kontan's issue of 29 December 2011). Recently, The New York Times prefers developing companies in the online media business.

The above is evident evidence that the paper, aka newspaper, is already entering the final round. Well, the online journalism system that puts Internet technology into a very popular [8]. In addition to being much more efficient and effective than print media that requires very expensive, online media is much more environmentally friendly [9]. Because online media does not need paper, which comes from forest trees. The speed and accuracy factor is the mainstay of the news based on online media [10]. However, online media is also very harmful when online journalists have no competence and honesty in journalistic work. For the ability of online journalists to make news, articles, photo and video news and a variety of other journalistic manuscript products, it is needed a technical guide so that online journalists understand their rights and obligations [11].

Based on the explanation above, some fundamental questions can be raised. First, allow the presence of an online journalism system with its online media to be the main trigger to roll the print media industry (offline journalism)? How is the advantage of online journalism compared to print journalism? Secondly, how is the fate of the future (Quo Vadis) online journalism in the industry of the mass media, is it the most ideal and effective form of journalism [12].

In this context, I would like to focus on the news function of the press for many reasons: news is the basis of the journalistic work, it is important to inform the public about events that are around them, and newspapers usually compete for achieving excellence in news dissemination. Also, I would like to investigate the future of the news function of printed press under the competition of electronic means in the period 2015-2025. For deeper understanding and elaboration, some important questions are proposed here:

What is the reality of the news function of the printed newspapers under the internet competition? What is the impact of internal and external operating environment factors on the reality of the printed newspapers' news function? What are the experts' perceptions towards these factors? Will the internet remain the most important electronic means of communication, and the strongest competitor of the printed media? What are the possible future scenarios for the news function of printed newspapers under the internet competition?

\section{Theorical Framework}

\subsection{Gatekeeper Theory}

Mass communication is a complex communication process. Mass communication usually relies on the media to convey a message to a broad audience. The use of mass media in mass communication aims to facilitate communicators to convey various information either in the form of entertainment, education, or social control [13]. According to Jalaluddin Rakhmat, the definition of mass communication is a type of communication addressed to several scattered, heterogeneous, and anonymous audiences through printed or electronic media so that the same message can be received simultaneously and instantaneous [14].

Mass communication often involves institutions or institutions such as companies engaged in the mass media. These companies include newspaper companies, magazines, television stations, radio 
stations, as well as companies in online media or websites. Jalaluddin Rakhmat defines mass media is an environmental factor that changes audiences behavior through the artistic process, operant or imitation (social learning). The mass media has two functions, namely the mass media can fulfill the need for fantasy and information [15].

The character of a mass media that can only communicate one way makes the institution or institution work hard to produce quality information without causing problems related to social life in the community. To prevent errors in the delivery of information in a mass media, it takes a supervisory body or is often referred to as gatekeeper [16].

Gatekeeper or goalkeeper is a person or group in an institution in charge of selecting information, ranging from the newly acquired data, the process of information processing, and the last screening process before being disseminated to the audience. For example, in a television agency or print media is usually gatekeeper played by editors, editors, journalists, and so forth.Cited by Kurt Zadek Lewin developed the concept of this theory in the field of psychology to understand the relationship between attitudes and behaviors. At first, this concept was widely used in the field of psychology, then it began to be used in the field of communication [17].

The gatekeeper decides what information should move to group or individual, and what should not. Through this process, the gatekeeper can remove the unwanted and controversial content in order to control the society and manage it.

Theory assumptions:

i. Media is networks of systems that are connected in complex ways, where the communicator decodes the symbols, then interprets and stores information to code them again in new symbols to present them to the audience.

ii. The communicator has the power to control the media content; the gatekeeper can determine how to select, add, withhold or display information, in addition to determine the formation of content and the timing of publication [5].

iii. The gatekeeper depends on several factors in making his decisions: the values and traditions of the society, as each society has its own political, economic and social systems, as well as the specific characteristics of the communicator, such as gender, age, income, social class, social background, professional competence, in addition to intellectual and ideological affiliations.

Based on the previous assumptions, it is obvious that the internet challenges the idea of gate keeping. This era has witnessed the end of the traditional gatekeeper role because readers are now finding their own ways to news online [3].

\subsection{News Room Culture Theory}

Working culture is a culture (values that have become customary) associated with quality or quality of work where a successful work, rooted in the values possessed and behaviors that become customary. These cultural values start from customs, religion, norms, and conventions that become a habit in the behavior of the work or organization. The culture of work is a set of overall inherent behavioral patterns in each individual in an organization. Building cultures means also enhancing and maintaining the positive edges, as well as attempting to habituating the specific behavior patterns to create a new shape better [18].

From the descriptions above that, the culture of work is a philosophy as values that become the nature, habits, and driving force shared by each individual in the work environment of an organization [19]. If associated with the organization, then the working culture in the organization shows how the organizational values are learned that are planted and expressed using specific means (vehicles) so many times, so that people can observe and feel it. The culture of work differs from one organization to another, and it is because of the foundations and attitudes of behavior reflected by everyone in the organization differently. The definite form of work culture will be beneficial because each member in an organization needs to pledge suggestions, even criticism that is constructive from the scope of his works for advancement in the institution, But the working culture will be unfortunate if the employee in an organization has a different opinion, because there is a 
difference between each individual in his opinion, energy, and mind, because each individual has a Skills and expertise according to their respective fields [20].

To improve the right working culture takes years to change, then it is necessary to reform that start from the attitude and behavior of the leader then followed by the subordinates, the formation of a culture of work begins The level of consciousness of the leader or appointed officer where the magnitude of the relationship between the leader and his subordinates will determine a separate way of what is carried out in a work unit or organizational device [21].

So, in this case, the work culture is formed in the working unit, or the organization stands, it means that the establishment of a culture of work occurs when the working environment or organization is in the face of problems, whether it is about organizational problems. Hall (1976) and Hofstede (1980) focused on the concepts of individual and collective cultures within newsrooms. This theory emphasizes that each press organization has a specific culture. It shows that there is a cultural experience exchange among the journalists within the working environment. Also, it helps to determine the cooperative mechanisms among the journalists in the newsrooms, their functioning and working methods, as well as their interactive styles.

Theory assumptions:

i. Organizational structures within newsrooms affect the way individuals behave. Workers in newsrooms adopt various ways of thinking and behavior; they communicate with their colleagues in different ways. This contributes in forming the journalism working environment [20].

ii. Types of cultures within newsrooms include constructive and defensive cultures [10].

iii. There are criteria of the cultural differences within press organizations according to the following: [21] The level of power given to individuals in the workplace; The way of managing crises within organizations; Individual and collective cultures; Duties and responsibilities of each gender in the workplace.

Organizational success begins with the discipline of implementing the company's core values. Consistency in implementing discipline in every action, rule enforcement and policy will encourage the emergence of openness conditions, which are always far from negative prejudice because everything is conveyed through facts and data Accurate (correct information). Furthermore, the situation that is full of openness will improve horizontal and vertical communication, foster personal relationships, both formal and informal among management, to grow the attitude of mutual respect [22].

In turn, the interaction between cross-sectoral and intercompany employees will nourish the spirit of cooperation in the form of mutual coordination of management or intersectoral employees, maintaining the management's expertise, supporting and securing every Management decisions, as well as fill and complement each other. This is the common goal of forming a working culture. So, the researcher aims to identify the impact of mainstream cultures within the newsrooms in the Egyptian state and private press organizations on the work flow, in view of the journalistic work environment interactions and the modern technological developments [23].

\subsection{Remediation Theory}

The daily development of media communication shows that to communicate, people are highly supported and require the use of communication media [24]. Nevertheless, the use of such media is adapted to the purpose of human communication. In the working world, print media, broadcasting and telecommunications/Internet is called as a tool of mass communication executor, so that the use of media is identical with mass communication [25]. Mass media practitioners utilize all three media types to convey a wide variety of ideas, information, entertainment data, and facts to audiences [26]. The medium of communication can not be established in mass communication because even through media, but the media is not a mass media, or more specifically, exchanged messages are Intern, just like the nature of messages on communication Communication, it is only indirectly occurred [27].

Jay David Bolter and Richard Grusin in 1999 offer a theory shows that new medium transforms older one, retaining some of its features while discarding others [28]. One media grows out of another, creating an entangled vine. None exists or even makes sense without those that came 
before; one media interacts with other media constantly by reproducing, replacing and making other changes. Bolter and Grusin call this process "remediation", they define remediation as "the way in which one medium is seen by our culture as reforming or improving upon another" [28]. Theory assumptions:

a. The most recent means of communication reshapes the previous and contemporary ones without abolishing them [28].

b. The internet as a new means of communication born of television and computer technology (image, sound, text, animation, film, drawing, writing and printing). Each means of communication aims to re-submit the content of the old one in a more recent and effective method [29].

c. The news medium attempts to conceal its presence to make the reader feel that its content is a part of the virtual reality.

d. The new technologies have resulted in the emerging of news media.

e. The news medium creates a tense relation between the visual environment and the real one [28].

In the light of these assumptions, it is assured that printed newspapers start to take advantage of the internet features; there is a widespread use of computer mediated communication technologies such as email, chat rooms, and bulletin boards, in order to allow the readers to express their opinions and to broaden their interaction with the news content [30]. Also, there is a trend among journalists to publish short and soft news stories to attract the readers.

\section{Method}

This is an exploratory future study. It uses the survey method to gather the required information about the constant and nonconstant factors affecting each of the concept of news function, the news function of the printed press, the characteristics of news medium, the roles of communicators, the nature of audiences, as well as the areas of competitiveness between the printed press and the internet. The study also used the comparative method to compare between the news articles published in electronic newspapers and those published in national and private ones in terms of content, format, construction and news function.

Concerning data-collection tools, the delphi method was employed to combine the experts' opinions on the future of printed newspapers' news function. A carefully designed list of questions were developed and refined in several rounds. Schedule interviews were applied with 22 experts in the field of media. Also, scenario writing style was used to formulate the scenarios of the printed newspapers' news function. The researcher used the interactive method in scenario-building which includes persistent, reform and radical scenarios.

In addition, qualitative content analysis was applied to analyze the content of a random sample of news articles during the period from 31/10/2015 to 18/4/2016. The sample included 60 news items in 12 printed and electronic newspapers, including the printed and electronic editions of Al-Masry Al-Youm, Al-Watan, Al-Youm7, Al-Ahram, Al-Akhbar, and Al-Gomhouriya. Regarding the methods of analysis, the morphological analysis method was employed to analyze and decompose the structure of the internal components of the studied phenomena which include the news item, the communicator, the audience and the means of communication (printed and electronic).

Moreover, the qualitative analysis was used to analyze the content of a sample of news articles published in the Egyptian national and private newspapers, as well as to describe and interpret the experts' opinions in order to formulate a set of possible scenarios. These methods and tools enabled the researcher to conduct a detailed study of the issue in question in a manner that has contributed to achieve the following reasearch purposes:

a. Descriping the factors affecting the future of the news function of printed press under the competition of the internet during the next ten years.

b. Interpreting the influences on the future of the news function of printed press, in addition to the challenges facing this function. 
c. Verifing the results by analyzing the content of a sample of news items in printed and electronic newspapers, in addition to examining the perceptions of experts about the future of printed newspapers' news function.

d. Evaluating the performance of printed and electronic newspapers, and how the printed press plays its news role.:

\section{Results and Discussion}

Any attempt to understand the future of the printed newspapers' news function under the competition of the internet should begin with a brief examination of the news content published by printed and electronic newspapers to provide a framework for analyzing the competitive relationship between printed and online journalism. The study showed that most of the news content published in electronic newspapers are in the form of news items, while most of them published in printed ones are in the form of a report or a news story, this helps the printed newspapers to achieve the news function in its comprehensive concept. The online published news items use archival images to achieve the rapid dissemination of news, while the paper ones are keen to publish live images of events. Electronic newspapers present one main title only, while the printed ones present one main title besides a lot of sub-headings. The reader of online newspapers can publish his own opinion, he can disseminate information, post photographs or videos; this has given rise to the emergence of citizen journalism as a form of journalism which enables people, who are not professional journalists, to report newsworthy situations around them.

In view of these findings and the results of interviews conducted with the experts, the researcher examined the future of the printed newspapers' news function under the competition of the internet through three scenarios; these scenarios rely on investigating external and internal factors affecting the news function in the printed newspapers under the competition of electronic means of communication. The external environment includes outside factors such as political, economic, social, and technical considerations that impact the press organization, while the internal environment is composed of the elements within the organization, including the characteristics of the news medium, the challenges facing it, the professional standards of publishing, the news story's writing methods, as well as the status of the communicator and the audience.

The first scenario (stability scenario) assumes the stability of the set of the previous external and internal factors. This scenario sees that political factors will remain unchanged in terms of the persistence of security restrictions and extreme levels of violence. The relationship between the press and the power will remain static; limitations on freedom of expression will be maintained in the coming years. According to this view, there will be no changes in the economic situation; high prices, wages decline and deterioration in the economic conditions resulting from the strengthening of the dollar will affect the printed newspapers negatively. Newspapers owners' financial crisis will last due to weak investment, low rate of importation and lack of advertising. The party newspapers conditions will still suffer from absence of funding and weak activities of political parties. Previous factors mean that press organizations will be unable to qualify journalists, or develop newsrooms, or meet audience needs.

Concerning social conditions, the audiences will pursue whatever issues they choose whether through printed newspapers or electronic ones. In this case, it is likely that the number of the internet users will grow owing to the eventual decreases in the connectivity cost and the widespread use of smart phones. These phones facilitate access to the internet or other communication media, so that various audiences can inform themselves regarding current issues and actions faster and easier than pursuing the printed newspapers. Within such context, the number of electronic newspapers and news sites will continue to increase, new forms of smart phones and tablets will be developed, technological developments will contribute to the development of news content of electronic newspapers, in addition, competition between printed newspapers and electronic means of communication will be exacerbated.

The second scenario (the creative scenario) assumes an evolution in the concept of the news function in the printed newspapers. The increased dissemination of news through printed newspapers is supposed. In the broader context, Egypt will enter into a political stability period. Comprehensive political pluralism will be achieved; there will be a wide margin of freedom of 
expression which will play an important role in developing the printed newspapers. Democratic climate will lead to increase the number of printed press publications, and motivate the political parties to reissue their journals. This will raise a journalistic competition which can develop the printed newspapers' news function. More broadly, political stability will have a pivotal effect on the process of economic development, investment rates will rise, and businessmen will issue additional newspapers and magazines.

Furthermore, the communicators' performance will be developed, the work system within the newsrooms will be better, so the news content of printed newspapers will be able to compete the content of electronic ones. Within such context, audiences' demand for the printed press will rise, as there will be a great awareness about the value of its news content and analytical services. The internet audiences will be limited to the youth. Accordingly, the news role of the internet will be limited due to the inaccuracy of its content, its lack of credibility, and its role in spreading rumors; the internet role will be confined to just the recreation and leisure activities.

The third scenario (pessimistic scenario) assumes the deterioration of the news function of the printed newspapers due to the deterioration of each of social conditions, working environment, situation of journalists, quality of news content and communicative practices of audiences. With regard to political conditions, the pessimistic scenario assumes the deterioration of the political situation and the tyranny of the ruling regime. Accordingly, there will be further restrictions on speech and press freedoms, state custody of the national newspapers will increase, as well as the private newspapers will be closed. More broadly, this scenario sees that there will be a general downturn in the economy; rising inflation will have a negative impact on the citizens' purchasing power. This will result in rising the costs of newspapers publishing, and closing down existing ones.

Within such context, readers will be diverted from printed newspapers because of their dissatisfaction with the presented news content. Their demand for the internet will increase due to the internet unique characteristics; it enjoys unlimited freedom, and enables the user to publish any information without censorship or restraint. Accordingly, a large number of printed publications will be closed; there will be electronic publications only, meaning that number of news web sites will increase, the news function of social networking will be activated, and the mobile phones' news applications will be commonly used.

\section{Conclusion}

The particular interest of this study is to paint a number of scenarios for the future of news function of printed newspapers under the competition of electronic communications in the period 2015-2025. The study reveals that there are three scenarios of this future, these scenarios include stability, creative and pessimistic scenarios. The stability scenario is the most likely to occur during the first five years of the study period (from 2015 to 2020).

According to the experts, the printed press will need a period of not less than five years to regulate the new concept of news function of the printed newspaper under the competition of the free and uncontrolled electronic means of communication. They see that this electronic media plays a crucial role promoting communication in the society.

However, our findings suggest that the creative or optimistic scenario will be realized in the next five years (from 2020 to 2025). Over this period, all the printed newspapers in Egypt will be able to consider the new concept of news function; they will provide readers with the required background information on the incidents and the important implications. 


\section{References}

[1] F. F. Lotan, "Making a positive internet through Socmed Agawe Guyub," Int. J. Commun. Soc., vol. 1, no. 1, pp. 9-16, 2019.

[2] M. A. El Din, The Art of Journalism, Third Edit. Cairo, 2005.

[3] P. Shoemaker and T. Vos, Gate Keeping Theory. New York: Routledge, 2008.

[4] U. Jandevi, "New media for increasing political participation in Indonesia," Int. J. Commun. Soc., vol. 1, no. 1, pp. 1-8, 2019.

[5] Wikipedia, "Gate keeping," Wikipedia, 2015. .

[6] The Economist, "Yesterday's Papers: The Future of Journalism," The Economist, 2005. [Online]. Available: http://www.economist.com/node/3896039.

[7] A. F. Wood and M. J. Smith, Online Communication: Linking Technology, Identity, \& Culture. New York: Routledge, 2004.

[8] C. M. Obama, "Normativity and the Problem of Look in the Emergence of Citizen Journalism," Adv. Journal. Commun., vol. 4, no. 1, pp. 1-7, 2016.

[9] J. Ball, "Distrust of social media is dragging traditional journalism down," The Guardian, 2019. [Online]. Available: https://www.theguardian.com/commentisfree/2018/jan/22/distrust-social-mediatraditional-journalism-fake-news.

[10] Readership Institute-Impact Study Culture Report, "A Profile of the Impact Newspapers and Their Departments," 2000.

[11] Mathew Ingram, "Most Americans say they have lost trust in the media," Columbia Journalism Review, 2018.

[12] A. David and R. Snow, Media Worlds in the Post-Journalism Era. New York: Aldine de Gruyter, 1991.

[13] T. Gitlin, The Whole World is Watching: Mass Media in the Making and Unmaking of the New Left. Barkley: University of California Press, 1980.

[14] J. Deane, "Media, democracy and the public sphere," in Media and Glocal Change: Rethinking Communication for Development, Buenos Aires: Consejo Latinoamericano de Ciencias Sociales, 2005, p. 178.

[15] R. E. Hanson, Mass Communication: Living in a Media World (Media and Public Opinion). London: Sage Publication, 2014.

[16] Rashem Rashem, "Public Sphere and the Power of Mass Media," The Circular, 2018. [Online]. Available: http://thecircular.org/public-sphere-and-the-power-of-mass-media/.

[17] K. Lewin, "Forces Behind Food Habits and Methods of Change, the Problem of Changing Food Habits," 1943.

[18] C. Thousand and C. A. Sage, "Media Organization and Production . Edited," pp. 139-142, 2003.

[19] I. C. Osita, I. O. R, and N. Justina, "Organization's stability and productivity: the role of SWOT analysis an acronym for strength, weakness, opportunities and threat," Int. J. Innov. Appl. Res., vol. 2, no. 9, pp. 23-32, 2014.

[20] A. Christine and S. Weiss, the Transformation of the Newsroom: The Collaborative Dynamics of Journalist's Work. 2008.

[21] Jandt, Dimensions of Culture. Sage Publication, 2006.

[22] A. McKee, The Public Sphere: An Introduction. Cambridge University Press, 2004.

[23] K. Kotler, Phillip., Keller, Marketing Management. New Jersey: Pearson Education, Inc, 2012.

[24] R. Nasrullah, Komunikasi Antar Budaya di Era Budaya Siber. Jakarta: Prenada Media, 2012. 
[25] D. McQuail, "Mass Communication Theory: An Introduction,” London: Sage Publication, 2009, p. 87.

[26] J. Alekander and R. Jacobs, Mass communication, ritual and civil society. London: Routledge, 1998.

[27] Hans Verstraeten, "Media, democracy and the public sphere: towards a reconceptualisation of the public sphere," South African J. Commun. Theory Res., vol. 26, no. 1, pp. 73-83, 2000.

[28] J. D. Bolter and R. Grusin, Remediation, Understanding New Media, Michigan. MIT Press, 2000.

[29] B. Cotton and R. Oliver, Understanding Hypermedia. London: Phaidon Press, 1993.

[30] D. Fadillah, "Strategi komunikasi pembentukan budaya organisasi," Humanika, vol. 14, no. 1, 2014. 